\title{
Voices from the Savannah: An Innovative Approach to Self-Publishing
}

\author{
Graham Diprose \\ Speos Institute London \& Paris \\ 13 Heathfield Drive \\ Redhill, Surrey, UK \\ grahamdiprose@gmail.com
}

\author{
Gary Roberts \\ Speos Institute London \& Paris \\ Apt 31, 384 Chester Road \\ Manchester, UK \\ gary@garyrobertsphotography.com
}

\author{
Amalia Toyas \\ Digiarts \\ UK
}

Ami.toyas@gmail.com

\begin{abstract}
'Voices from the Savannah' is a prestigious 'Coffee Table' book featuring many of the most important opinions involved in East African Wildlife conservation such as Dame Jane Goodall and Dr Dame Daphne Sheldrick. The author, Gary Roberts, considered it vital that the book was bilingual in English and Swahili, so that the message could reach the widest audience of those capable of making a significant difference to the present catastrophic losses of wildlife numbers and habitat.
\end{abstract}

Few publishers capable of producing the quality of book required, were even willing to consider backing a book with bi-lingual text, no matter how outstanding the photographs or significant the 'Voices' gathered together for this volume. This lead us to seek alternative approaches to Book Design, Publication, Sponsorship, Marketing and Distribution, using a combination of the very latest technologies available via the self-publishing route. This paper describes the innovative online workflows used, with the Author based in Manchester, the Editor in Surrey, the Translator in Tanzania and the Book Designer on a Greek Island, combined with the advantages now available for short digital print runs and longer Offset Litho runs to massively reduce costs per book and ensure it's vital message reaches the widest possible audience and also can provide additional publicity and profits to help fund the major wildlife charities involved.

Self-publishing. Prestigious book design. Editing. Campaigning. Bilingual. Digital printing. Colour management. Innovative publishing workflows.

\section{INTRODUCTION}

Over twenty years Photo-journalist and Zoologist, Gary Roberts has been investigating many East African wildlife conservation issues in collaboration with The David Sheldrick Wildlife Trust and with SANA (Saving Africa's Nature Organisation).

In his research, he was shocked by statistics such as a $90 \%$ fall in the wild lion population since first visiting the region in the 1990s. He became very concerned that, along with the continuing war against ivory and rhino horn poachers, these stories were receiving only minimal coverage amongst any of the significant media Worldwide

Many of the famous conservationists that Gary Roberts interviewed, both in Africa and worldwide, also seemed unsure if anything could be done to help to make people aware of the growing carnage.
Constantine Coucoulis, Chairman of SANA and Gary Roberts concluded that the best way to show the truth about what was happening in East Africa was though the words and opinions of those in the field, who had given their life-work to fight for the wildlife or who could explain the impact of man and climate on the ecosystem involved.

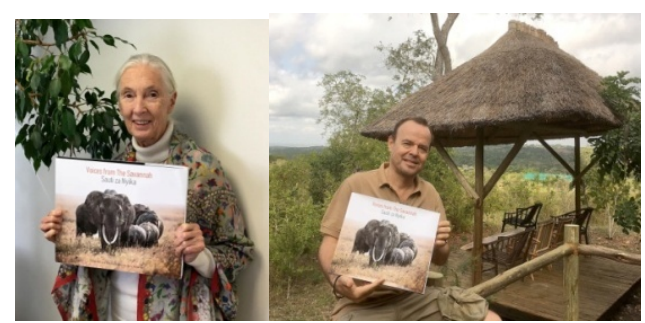

Figure 1: Dame Jane Goodall \& Constantine Coucoulis each with one of the first digital copies of Voices from the Savannah from November 2015

The initial idea developed into producing a book "Voices from the Savannah" to the highlight the 
plight of the wildlife and their environment. Each "Voice" interviewed could express their hopes, opinions and fears, with positive ways in which the reader could help and support the individuals involved via their websites and social media.

\section{BOOK SPECIFICATION}

Each 'Voice' would be supported by a series of either very hard-hitting or attractive photographs taken by Gary Roberts, while he was working on assignments concerning all the issues involved.

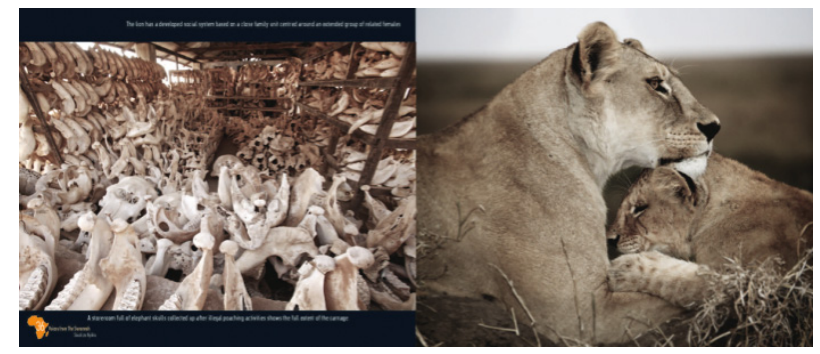

Figure 2: A store-room filled with the skulls or recently poached elephants is even more poignant against an image about the close social groups formed by lions.

It was decided that the "Voices" should not only be the famous conservation 'names', or top worldwide academics, but also come from the actual people involved 'on the ground'. This led to the conclusion that if the book was to make any difference among the peoples of East Africa, it would need a Swahili version or to be bi-lingual to ensure that there was a vital dialogue across both national and cultural boundaries that everyone could understand.

There are numerous beautiful wildlife books sold across the booksellers, airport lounges and hotels throughout East Africa but the hope has always been that this book would be far more than just an attractive tourist souvenir to take home.

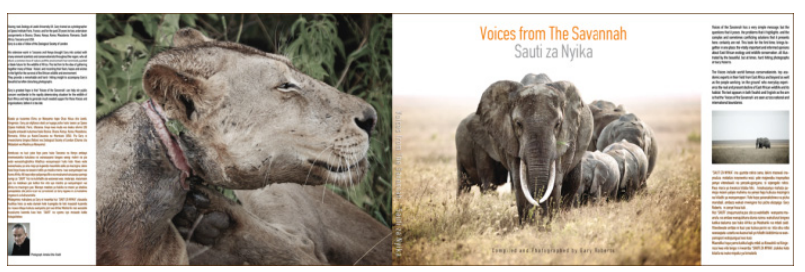

Figure 3: The final Dust Jacket Cover featured English and Swahili along with a beautiful image of a herd of Elephants and a male lion badly injured by a snare.

Thus, the book had to perform a dual role. It needed to be a beautifully designed and printed large "Coffee Table" hard back book to compete with any others, but also be attractive enough to be placed in embassy and company receptions, at the front desk of government ministries, and the lounges of luxury tourist lodges. It was also hoped it would find a place in many universities, colleges and school libraries in Africa and worldwide.

The problem rapidly became how to produce a beautiful high quality "Coffee Table Book", when major publishers refused to consider publishing bilingual text and demanded considerable editorial control of both the images and 'Voices' opinions. The only possible answer was to consider SelfPublishing with all its complexities and risks.

\section{PREVIOUS EXPERIENCE WITH SELF- PUBLISHING LONG DISTANCE WORK-FLOWS}

Gary Robert's first attempt at designing the book was using Apple iBooks. This gave a rough outline but the templates were very limited when trying to make a prestigious "Coffee Table Book" and he only achieved a few successful looking spreads. He concluded that more expert help was needed and consulted with a colleague from Speos Institute, London, Graham Diprose, who had already worked extensively in authoring and editing several prestigious books, and had recent experience of a successful Self-Publishing Project "In the Pursuit of Light" made to promote a young award-winning Romanian Photographer and Artist, Felicia Simion.

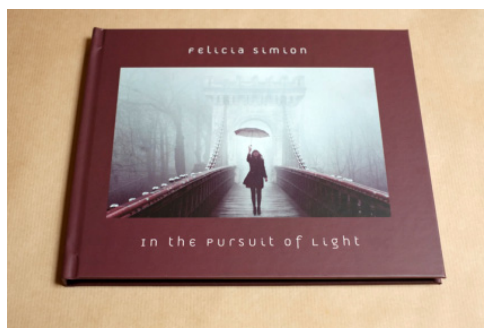

Figure 4: "In the Pursuit of Light" created in August 2014 for Photographer Felicia Simion.

The project had an interesting workflow that was relevant to the "Voices of the Savannah" project, as Felicia Simion was supplying photographic images and copy from her home in Craova, Romania, book and graphic designer, Amalia Toyas now worked from the Greek Island of Ikaria and Graham Diprose, as editor, was based in Redhill, Surrey.

Having researched a number of self-publishing book companies, Blurb was chosen for an ability to avoid using any templates whatsoever, but rather to use the flexibility of 'Adobe In Design' along with the ability to totally control our Colour Management of images. Having considerable expertise in these fields, using 'Blurb' gave Amalia Toyas and Graham Diprose the complete management of design, typography and production, that many other similar self-publishing sites could not offer.

The book featured a series of stunning self-portraits that Felicia Simion had taken between the ages of 
13 and 19 years old, some of which had already won major international accolades. This book was not created to be a "Best Seller", but rather as a very prestigious "Business Card Plus" in Standard Portrait $25 \mathrm{~cm} \times 20 \mathrm{~cm}$ Image Wrap and Soft Cover, where a further short run can always be printed 'on demand'. In this role, the book is a great success.

\section{APPLYING OUR SELF-PUBLISHING SKILLS TO 'VOICES FROM THE SAVANNAH"}

Gary Roberts was still collecting new "Voices" during early 2015 , so although we estimated the book to be about 100 pages, this would regularly change as the project became better known and he received more exciting offers to contribute.

In his first attempt, Gary Roberts had naturally grouped images of wildlife by where they were taken and often by where the Voices lived. As an editor, Graham Diprose pointed out that a good, well captioned lion shot was all that really mattered, rather than if it came from a specific game reserve.

This illustrates the role of an experienced Editor on any book project, whether conventionally or selfpublished. A book is a journey from cover to cover, and whether a novel or textbook, it still needs a 'flow' and to develop themes and ideas. The idea with "Voices from the Savannah" was that some spreads would be uplifting, while others would show the utter inhumanity and the carnage that East African wildlife is presently suffering. We chose to 'mix up the Voices' so that the opinion of a top conservationist had equal page space to a retired train driver who had witnessed the losses in animal numbers and environment from his cab window for the past 30 years. Both added impact to the overall story that the book was narrating.

Amalia Toyas developed a very flexible grid that held the book design together, but allowed each turning of the page to be a new visual experience. The page number in the map of Africa was one of several clever features that all added to the quality look and feel of the final book.

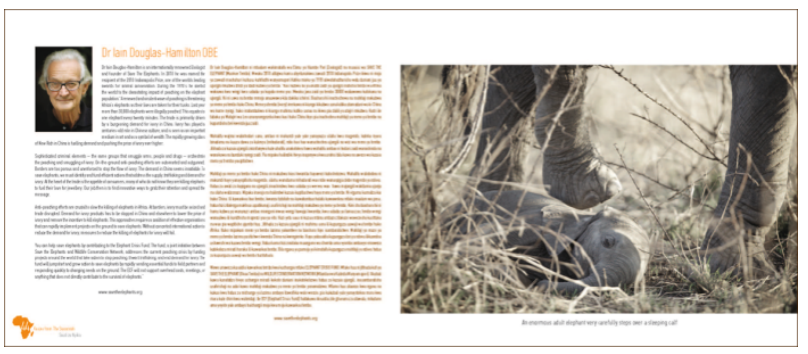

Figure 5: Dr lain Douglas-Hamilton OBE, an expert on elephant conservation, showing a double page spread.
While, in principal, we wanted a very prestigious Large Landscape $(33 \mathrm{~cm} \times 28 \mathrm{~cm})$ Hardback "Coffee Table" book that would comfortably grace the receptions of top companies and institutions, we were concerned that many poorer schools and individuals, would be unable to afford, or access, a copy. One advantage of self-publishing is that we could also specify a second version as a smaller Standard Landscape $(25 \mathrm{~cm} \times 20 \mathrm{~cm})$ Softback book. We asked Amelia Toyas to design an initial twenty-one sample pages, so we could see if it was possible to maintain a readable text size and keep the 'look' of the larger book, on a smaller cheaper version. This is where having an excellent book designer that is using 'Adobe In Design' rather than templates proved vitally important and we were all delighted to discover that this idea could also work.

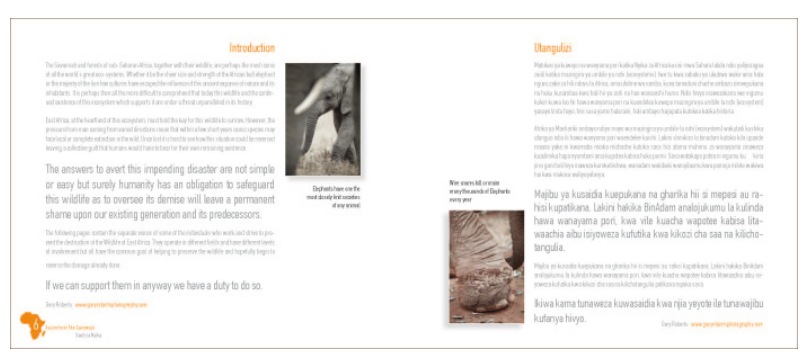

Figure 6: A double page spread taken from the draft design for a smaller $25 \mathrm{~cm} \times 20 \mathrm{~cm}$ version of the book.

Again, no major publisher would consider making two different format versions of the same book that might one day compete with each other, which is another big advantage of the self-publishing route.

Presently, we are holding this second part of the project in abeyance, while we concentrate on the financing, publicity and distribution of the main book, but it is very advantageous to know that this cheaper version would also work in practice.

\section{DEVELOPING A SUCCESSFUL WORKFLOW}

For "Voices from the Savannah" we used the same technique to plan the book with the actual page number, detail of the content on left (even numbers) and right (odd numbers). We also numbered each spread and tracked who had the low and high resolution images. Initially we asked Gary Roberts for low res Jpeg images $(25 \mathrm{~cm}$ on the longest side at 72dpi giving a file-size of about 970k). These were easy to e-mail attach to send to Amalia Toyas working on the Greek island of Ikaria.

With Felicia Simion's book, Graham Diprose and Amalia Toyas had already developed a workflow to edit the pages and spreads into the right order and track the images. This was done using a simple Excel Workbook, so that it was easy to move one double page spread ahead or behind another. 


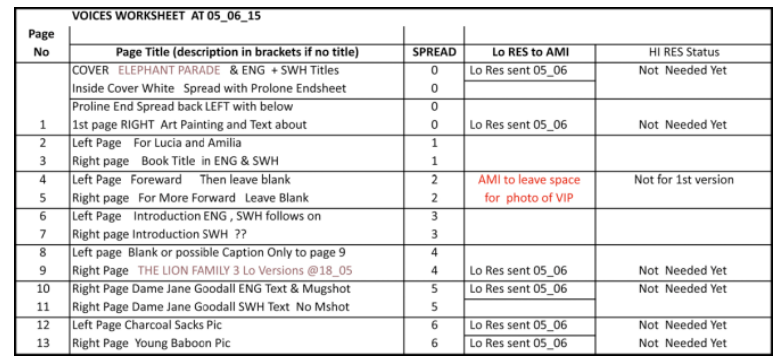

Figure 7: Part of the workbook showing the page and spread numbers and track of high and low res images.

Photographer and author, Graham Diprose had a fully calibrated computer monitor as did graphic designer Amalia Toyas and from time to time we conducted some successful tests to check that what we were both seeing on our screens, some $3,000 \mathrm{~km}$ away, actually matched. This remains, of course, vital in any workflow between creatives, as it prevents someone with an uncorrected monitor changing colours or densities of a correct file, to make it look right on their bad screen display.

The low resolution images were suitable for the 'Adobe In Design' layout and to make low res. pdf's of a single or number of spreads, to send back for review. Each file was tagged $\mathrm{LO}$ or $\mathrm{HI}$ in the filename to ensure that no low resolution images could find their way into the final finished book.

Colour calibrated high resolution images were sent using 'We Transfer", in batches if necessary. These were all '300dpi non-compressed RGB Tiff files' in 'Interleaved Pixel Order' and 'IBM PC Byte Order'. We chose to have a low-resolution version of the book using 'Adobe In Design' running continually, as more new pages were added. Also, we made a high-resolution sample of the first 27 pages that Gary Roberts could show to potential contributors and sponsors, on a laptop screen pdf.

It was very useful to have Amalia Toyas send back a low-resolution pdf of 'the book so far', every week or so, so we could see how the page to page flow and navigation of the book worked narratively and visually with the experience of turning each page.

\begin{tabular}{|c|c|c|}
\hline \multirow{2}{*}{\begin{tabular}{|c} 
Page \\
No \\
\end{tabular}} & Other Contex Pictures on Spread QUESTIONS ISSUES & $\begin{array}{l}\text { Text Tracking } \\
\text {. }\end{array}$ \\
\hline & NB This Cover is Imagewrap but may also go Soft smaller & $\begin{array}{l}\text { Front Cover Has Text in ENG \& SWH } \\
\text { We have the final Cover Caption }\end{array}$ \\
\hline 1 & This is acting as a a Frontispiece !! & $\begin{array}{l}\text { Cover Caption goes here too } \\
\text { Front matter Text to goto Ami }\end{array}$ \\
\hline 2 & Ignore pages $3 / 4$ in Gary pdf Version & \\
\hline 4 & Forward to be in ENG \& SWH With Photo of Writer & Cover Front matter Text to Ami \\
\hline 5 & Need a Cameo Filler Pic? No to worry as yet & \\
\hline 6 & English First & 2 Files Introduction ENG \& SWH \\
\hline & Maybe eed a Cameo Filler Pic? & 2 Files Introduction ENG \& SWH \\
\hline 8 & & \\
\hline 9 & Make extra sky in Photoshop GARY to do on HR & We have the final Caption \\
\hline 10 & This is 36 and 37 in Garys pdf Version & 2 Files Jane $G$ ENG \& SWH \\
\hline 11 & Although long...Might need a Cameo Filler Pic? & Need fixing SWH text in Paragraphs! \\
\hline 12 & OK as is on crop to leave room for both spread captions & We have the final Caption \\
\hline 13 & Probably crop to $28 \mathrm{~cm} \times 33 \mathrm{~cm}$ GARY TO DO & We have the final Caption \\
\hline
\end{tabular}

Figure 8: Another part of the spreadsheet showing page numbers, notes and tracking text and captions.
Another part of the same spreadsheet (illustrated here as a separate section, covered general notes and tracking the text in English (ENG) and Swahilli $(\mathrm{SWH})$ and also the captions, which were written only in English to maintain the clean looking design

One of the most challenging parts of "Voices from the Savannah", particularly for authors, editors and designers was the Swahili text and translations. These tended to arrive in many formats from jpeg to pdf, but generally had few or no paragraph breaks and randomly sections could often be noticeably longer than the English text. This made copy-fitting or leaving a suitable space for when a Swahili translation finally arrived, an impossibility. We relied on the odd county or person's name to endeavour to match to the English text and place paragraph breaks in the same spot. Khalid Mtwangi did an amazing job with the Swahili translations and also with the final proof reading, as it was an un-nerving experience for us when the auto spell check flashed every single word on the page in red.

Following discussions, Amalia Toyas decided that all Swahili text should be in brown and English text in black. This simple device made it easy for anyone reading the book in either language, to turn a page and identify the start of their "Voices" text.
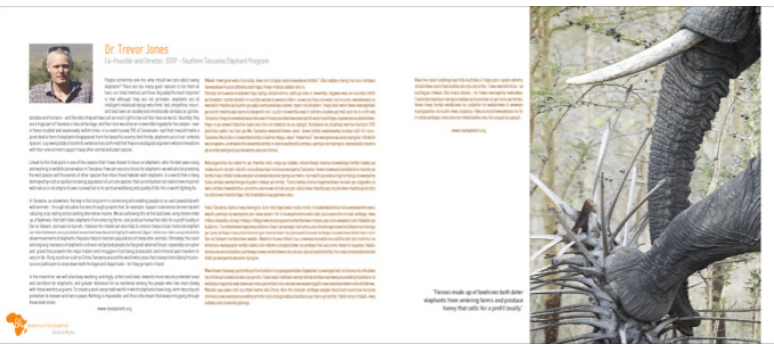

Figure 9: A spread showing how the English and Swahili text altered in length from one paragraph to another.

\section{CONVERTING TO CMYK AND UPLOADING THE BOOK AND COVER TO BLURB}

Even when working with 'Adobe In Design', Blurb still offers some extremely useful templates and calculators for the designer to fill in the paper stock, number of pages and end pages, in order to get the spine width correct, both on the bound hard-cover and the dust jacket. There are similar procedures for image wrap or soft-back covers too. Each time we added pages, even a single leaf, this had to be re-calculated, re-entered and re-converted to pdf.

For 'Voices from the Savannah', we always worked throughout with 'Adobe RGB' image files, as this was a more familiar workflow for photographers Gary Roberts and Graham Diprose. Blurb provide a CMYK profile that can be downloaded as the 'Device to Simulate' and for the final conversion. 
This is based on the HP Vivera pigment inks that are used in Blurb's digital ink-jet printing workflow.

As with most ink-jet printing, 'Perceptual' is the preferred 'Rendering Intent' to preserve subtle gradients and 'Black Point Compensation' is ticked to improve the blacks in shadow detail. All images are then converted to CMYK using Blurb's profile and the file is then saved as a pdf to upload to Blurb online. The cover is always an additional file. Blurb run a very useful checking routine as the book is uploaded online for every file. At our first attempt, this did report one error where we had not replaced a low resolution file with the high res image. There are well over 100 images in the book, so we were not unduly surprised at one slip-up and were quickly able to correct the mistake.

It is important to follow Blurb's instructions exactly whether using their 'BookWright' templates or 'Adobe In Design'. Graham Diprose was asked to help a photographer friend who had decided that to ensure that all his pictures came out in perfect Black and White, he would turn them all to 'Greyscale' rather than 'De-saturated Adobe RGB' and was horrified when his book arrived and every image had an unpleasant pink cast on it.

\section{THE FIRST BOOK AND CORRECTIONS}

After almost a year from the initial concept of producing 'Voices from the Savannah', the very first copy was in our hands by mid November 2015.

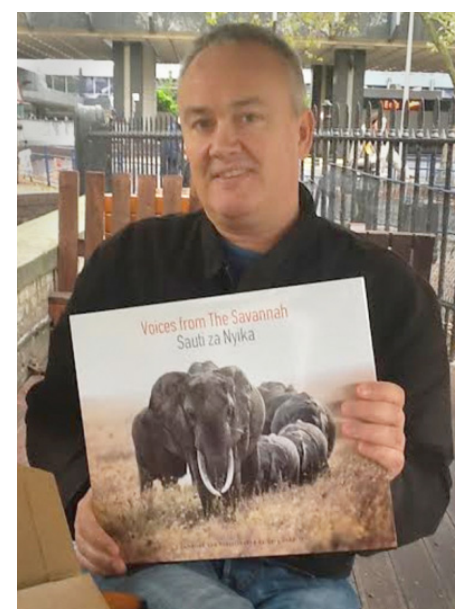

Figure 10: Author Gary Roberts holding the very first copy of 'Voices from the Savannah' (November 2015).

Generally, we were delighted both by the 'quality' and 'feel' of the book, and the reproduction of most of the photographs. However, there were a couple of typo's and despite our considerable expertise in colour management across both RGB and CMYK colour spaces, there were some images that were not exactly reproduced as we might have expected.
We went back to check these images carefully, but could see no obvious errors in our settings for them. While all other photographs were perfect. it still remains to this day a mystery why these few images were too light or had a slight contrast shift.

There was no alternative but to make an image on our colour calibrated monitors that 'looked wrong' to us, but that should correct the problems and then to run a second book. This next time it was perfect. Having experience of conventional book publishing where any error is reproduced, perhaps 3-5000 times by the horrible moment that it is spotted, any lack of skills in self-publishing can be more than negated by being able to publish a single copy, correct errors and then repeat until it is finally right.

We produced the very first book without the 'forward' by the ex-President of Tanzania, as our East African contact had to patiently wait for a couple of months to see him to get the text and Swahili translation. But this did mean that we could check everything else while we were waiting. The second book ran with his additional very significant text to add to our other most prestigious voices.

\section{EXPLOITING THE OPTIONS AVAILABLE IN SELF-PUBLISHING}

While many other self-publishing book companies provide similar options, being already familiar with the Blurb workflow had made it an obvious choice.

Having a dust jacket hard-cover makes the book look and feel exactly the same as any other from established publishers. Adding end sheets in grey, white or black adds to the overall 'quality feel' to the publication and is well worth the extra $£ 2$ cost.

There is an interesting choice of Matt, Lustre or Pearl paper. Care needs to taken when changing from one paper to another as the Standard sheets are $118 \mathrm{gsm}$, most others are 148gsm and the Proline Pearl Photo paper is a heavy $190 \mathrm{gsm}$. This will obviously affect the cover and dust jacket as it affects the overall thickness of the book.

The heaviest paper may sound the best, but when making a large Coffee Table book and hoping to ship many copies to Africa, the weight of a single book and bundle of twenty-five, can become a serious issue.

We tried both the Proline Uncoated at about $£ 80$ per book and the Premium Lustre at about $£ 66$ for a single copy. Discounts were then available for a longer run and it was always well worth looking out for special discounts of $25 \%$ or even up to $40 \%$ whenever we wanted to run new versions or extra books. Once we got a correct copy with a couple of 
sponsors, we ran 25 copies while a $40 \%$ discount was available and these were distributed to the most important 'Voices' and to potential sponsors.

It was possible to remove the Blub Logo from the book, or put in our own, but this added $25 \%$ cost to each book and we saw no advantage in taking up this option and reducing projected profits for the various wildlife charities that we hope will benefit from sales. We were happy it was a Blurb book.

\section{SPONSORSHIP AND EXTRA PAGES}

Being able to add additional last minute 'Voices' or Sponsorship pages with ease, has really helped to make this project viable, and as going to press on this paper, further additions to the book from both these sources are highly likely.

While we are selling the book via Amazon, the most significant sales are via the various wildlife centres and prestigious tourist lodges that feature in the book. 'Voices from the Savannah' is a 'not for profit enterprise' where, providing that publication and shipping costs are covered, we are happy for the wildlife charities to sell the book at a higher price and benefit from the profit towards their work.

\section{FINANCING A LONGER PRINT RUN OF 'VOICES' USING BLURB OFFSET LITHO}

We plan to continue to show the book to more high level contacts in the US and East Africa, acquire appropriate new sponsors and add more additional pages for those wishing to support the project.

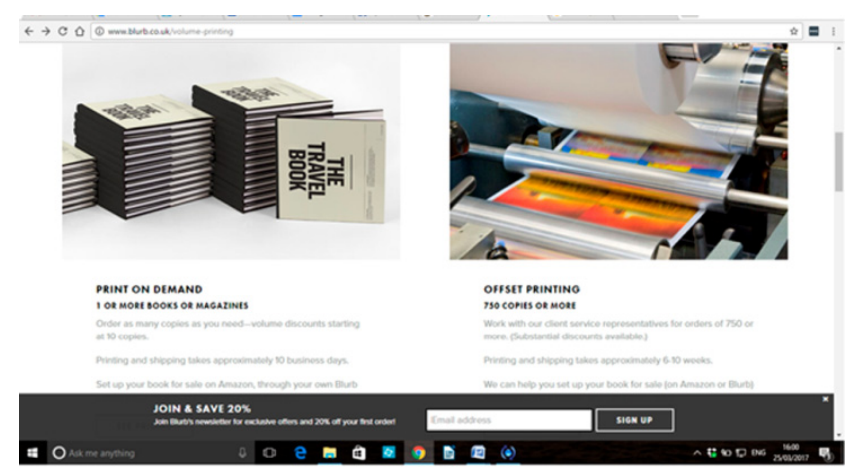

Figure 11: Screenshot of Blurb Books website showing new short and larger volume print run options.

Another reason for choosing Blurb, is a recent addition to their services where, when we have raised enough sponsorship money, we will plan to make a print run of 750 books, or more. Blurb will run books using offset litho rather than digital printing at vastly reduced costs per copy, estimated in our case at between $£ 25$ and $£ 30$ a copy. This would allow the book to sell retail at about $£ 60-$
$£ 75$ by wildlife charities making a healthy profit towards wildlife conservation as well as getting the 'Voices' message into a much wider public domain.

Printing and shipping takes about 6-10 weeks, as we understand that the printers are based in China. However, it is possible to print on one of the same paper stocks used in digital printing, so, as far as the colour management of the various technologies allow, it should be possible to mass-produce a book as pleasing to the sponsors, as the very short runs that we have already undertaken.

\section{ARCHIVAL QUALITY OF BLURB BOOKS}

Graham Diprose has previously delivered papers (with Mike Seaborne) to EVA London, Florence and Berlin, concerning the long-term archiving of digital imaging files and the fragility of data in storage and during regular migration. The conclusion was that institutions should seriously consider also archiving the most important parts of their photographic collections as reduced size pigment ink jet prints onto an acid free art paper,

It observed that old paintings made 500 years ago using non-fading pigments retained far more accurate colours, true to the day that they were painted, than most dye based photographic colour prints from 40 years ago. The losses from data migration of digital photographs and vast changes in technology, from as little as 25 years ago, is becoming an increasing concern. Already many museums do not have the skill-set or the funding to ensure successful long term digital data image preservation into the $22^{\text {nd }}$, let alone the $23^{\text {rd }}$ century

Blurb books use the same HP Vivira pigment inks in their book publishing that were found to have the longest life in our previous research. The highquality paper used, and very nature of a book means images are protected from UV light deterioration. One could easily conclude that making a Blurb book is a truly excellent and very sure way of sending this important series of leading 'Voices' opinions and the very poignant images of East African wildlife, down into the future to our great, great, grandchildren. Sadly, these photographs of many of these creatures are likely to be the only experience that they will ever have of them.

\section{CONCLUSION}

'Voices from the Savannah' brings together many different aspects of technology, most already known, but possibly not used together before in conjunction with each other. It demonstrates that very complex design and editing projects can be successfully completed by authors, editors, 
designers and book self-publishers all working in totally different parts of Europe, or even, the world.

Having achieved a correctly produced 100 page 'Coffee Table' book with sponsors pages added on request, the book is being financed without any major capital outlay and is already very successful in media interest, response and publicity.

By maximising the ability to inexpensively produce two, or twenty, or possibly in due course up to 2,000 copies, 'Voices from the Savannah' can truly support East African Wildlife Conservation both financially and in its powerful message to the world.

\section{REFERENCES}

BBC (2015) 'Ten years' to save Africa's wildlife.

BBC World Service, 22 September.

http://www.bbc.co.uk/programmes/p0336bj9.

(accessed 20 April 2017).

Blurb (2007-2017) Blurb Books, UK.

http://www.blurb.co.uk (accessed 20 April 2017).

Burrows, T. (2015) Voices from the Savannah:

Poignant images show fragile existence of Africa's wildlife which could face extinction within years due to money-hungry poachers. Daily Mail, 22

September. http://www.dailymail.co.uk/news/article3242343/Voices-Savannah-Poignant-imagesfragile-existence-Africa-s-wildlife-face-extinctionyears-money-hungry-poachers.html (accessed 20 April 2017).
Diprose, G. and Seaborne M. (2013) Back to paper? An alternative approach to conserving digital images into the twenty-third century. In J. P. Bowen, S. Keene \& K. Ng (eds.), Electronic Visualisation in Arts and Culture., pp 57-72. Springer Series on Cultural Computing.

Diprose, G. and Seaborne M. (2011) An alternative approach to conserving digital images into the $23^{\text {rd }}$ century. In J. P. Bowen, S. Dunn \& K. Ng (eds.), EVA London 2011: Electronic Visualisation and the Arts, UK, 6-8 July, pp. 132-138. Electronic Workshops in Computing, BCS.

Roberts, G. (2015) Voices from the Savannah. Blurb Books. http://www.blurb.com/b/7285529voices-from-the-savannah (accessed 20 April 2017).

Roberts, G. (2015) Voices from The Savannah: Gary Roberts' stunning photos of African wildlife. The Telegraph.

http://www.telegraph.co.uk/news/picturegalleries/w orldnews/11876892/Voices-from-The-SavannahGary-Roberts-stunning-photos-of-Africanwildlife.html (accessed 20 April 2017).

Roberts, G. (2016) Voices from the Savannah. Blurb, Amazon. https://www.amazon.com/VoicesSavannah-Gary-Roberts/dp/1367356970 (accessed 20 April 2017).

Simion, F. (2014) In the Pursuit of Light. Blurb Books. http://www.blurb.co.uk/b/5514602-in-thepursuit-of-light (accessed 20 April 2017). 